\title{
La biografía como identikit: La luz negra, de María Gainza
}

\author{
Biography as Identikit: \\ La luz negra, by María Gainza
}

\author{
PATRICIO FONTANA \\ ${ }^{a}$ CONICET, Universidad de Buenos Aires, Universidad Nacional de las Artes, Argentina. \\ Correo electrónico: patriciofontana@hotmail.com
}

\begin{abstract}
En este artículo se propone un análisis de La luz negra, de María Gainza, que hace especial hincapié en cómo en esta novela se advierte un experimento con la biografía que implica la puesta en crisis de varios presupuestos que permiten que ocurra la llamada "ilusión biográfica". En este sentido, a partir de diversas consideraciones teóricas sobre la escritura biográfica, se argumenta que La luz negra postula una poética biográfica que apuesta por lo indefinido y lo impreciso, y no por el apego a los hechos y a la exactitud documental que caracterizan la escritura biográfica más canónica. En razón de esto, se argumenta que esta novela sugiere en última instancia que la mejor biografía es la que no se escribe, la que se detiene antes de que termine la búsqueda de información previa a la escritura.
\end{abstract}

Palabras clave: biografía, novela, hechos, nombre propio.

This article aims to analize La luz negra, by María Gainza, placing special emphasis on how this novel experiments with the biography as a gender and questions several assumptions of the socalled "biographical illusion". Based on various theoretical considerations on biographical writing, it argues that La luz negra's biographical poetics dwells on the indefinite and imprecise, instead of the attachment to facts and truthfulness documentary that characterize the canonical biographical writing. The final assumption is that this novel suggests that the best biography is the one that is not written, the one that is interrupted before the search for information is thoroughly completed.

Key words: biography, novel, facts, proper name. 
Una cosa es buscar algo, incluso por toda la vida, invirtiendo tiempo y energía. Y otra cosa es encontrarlo y no tener qué buscar.

\section{(Carlos Godoy, La construcción)}

En las primeras páginas de su libro Biography, Alan Shelston se demora en la reivindicación de la novela que, a comienzos del siglo XX, hicieron Henry James y D. H. Lawrence al oponerla, explícita o implícitamente, a la biografía. Shelston apunta que, en ambos casos, estos escritores aseguraron preferir la novela en razón de la libertad de la que gozaría el novelista en oposición con el biógrafo que, maniatado por las demandas de exactitud y atención al detalle, no podría alcanzar esa "forma superior de verdad" (1977: 1, traducción mía) que sí le estaría habilitada a aquella. En contraste con la de la novela, la "verdad" de la biografía sería una verdad poco sofisticada, al alcance de todos. En esas mismas páginas, por lo demás, Shelston no solo recuerda que esos novelistas olvidaban que sus predecesores a menudo habían necesitado hacer pasar sus novelas por pseudobiografías, sino que además sostiene que el interés por la biografía, uno que la novela nunca menguó, se debería a la apelación que ella hace a la curiosidad de los lectores por espiar la vida de otras personas, en especial si fueron célebres, como también al deseo de conocer "qué pasó exactamente" (1977: 3), que es lo que aquí me interesa.

La cuestión de los "hechos" - del "qué pasó exactamente"-como una limitación del biógrafo aparece centralmente en el ensayo de Virginia Woolf sobre las biografías escritas por Lytton Strachey titulado, algo engañosamente, "El arte de la biografía". Allí Woolf asegura que la biografía

[...] impone condiciones, y esas condiciones son que debe estar basada en los hechos. Y cuando hablamos de los "hechos" de una biografía aludimos a aquellos hechos que otras personas, además del artista, pueden verificar. Si el biógrafo inventa hechos como los inventa un artista -hechos que nadie más puede verificare intenta combinarlos con hechos de la otra clase, ambos se destruyen mutuamente. (2012: 156)

El argumento de Woolf enseguida se vuelve más complejo porque advierte que, por supuesto, no es sencillo determinar bien qué es un "hecho". De todos modos, no solo establece un distingo entre escritores de ficción y biógrafos en razón de la mayor libertad de los primeros con respecto a las ataduras a las que estarían condenados los segundos, sino también a propósito de la intensidad y, sobre todo, la distinta perdurabilidad de lo que cada uno pueda lograr: "Ni siquiera el doctor Johnson creado por Boswell vivirá tanto como el Falstaff creado por Shakespeare. Micawber y la señorita Bates sin lugar a dudas sobrevivirán al sir Walter Scott de Lockhart y a la reina Victoria de Lytton Strachey. Porque están hechos de un material más duradero [...]" (Wolf 2012: 159). 
Woolf, entonces, al menos en principio, define los "hechos" como aquello que otras personas pueden verificar. A propósito de esto, habría que considerar que una biografía es un texto que solicita o al menos postula un lector que pueda completarla o ampliarla y hasta escribir otra. La biografía es un texto abierto y no cerrado o autosuficiente: siempre apunta a un más allá en el que el lector podrá continuar el texto de diversos modos, decir lo que allí no se dice, corregirlo, expandirlo o tan solo verificarlo ${ }^{1}$. La "débil acumulatividad del género" a la que se refirió el historiador Jacques Revel (2005: 217), y que en el texto de Woolf es también una hipótesis para deslindar biografía de ficción, y artesanía biográfica de arte novelesco, implica en última instancia que toda biografía es germen o anticipo de otra: de nuevos textos biográficos que ratifiquen, rectifiquen, amplíen o agreguen. Aunque el mercado editorial insista en ese rótulo, la biografía no puede ser definitiva, no en el sentido en que sí lo son el Quijote o Madame Bovary. La última palabra sobre un biografiado es escurridiza y, en última instancia, impronunciable. Ninguna biografía se impone definitivamente ${ }^{2}$. La biografía es un género no "saturable", en el sentido en que Jacques Derrida (1994) usa ese adjetivo en "Firma, acontecimiento, contexto".

Las dos novelas de la escritora y crítica de arte argentina María Gainza, El nervio óptico y La luz negra, publicadas en 2014 y 2018, no son biografías ni tampoco biografías noveladas pero sí son textos que, desde la novela, experimentan con el género biográfico o con lo que podríamos llamar, de manera más amplia, materiales biográficos. En este trabajo me detendré en especial en la segunda, La luz negra, pero antes quiero referirme a las dos en conjunto a propósito de la cuestión, planteada por Woolf, de la relevancia en la biografía de aquello que otras personas pueden verificar. En la contemporaneidad, y en razón de la creciente accesibilidad de la información y los archivos gracias a Internet, el lector puede involucrarse muy activamente en la lectura de un texto biográfico o de uno que, como estas dos novelas de Gainza, trabaja con materiales biográficos. Su presencia en estos libros pone en suspenso su estatus como obras orgánicas, cerradas o autosuficientes.

El nervio óptico combina o entrecruza, en la mayor parte de sus capítulos, el relato en primera persona de los avatares existenciales de una narradora que es crítica de arte o de sus amigos o parientes cercanos con pantallazos biográficos de algunos artistas plásticos: Cándido López, Henri de Toulouse-Lautrec o Hubert Robert, entre otros. Estamos ante una ficción autobiográfica o autoficción que se tiñe de verdad -no de verosimilitud-al rozarse o fundirse con esos extractos biográficos en los que se reflejan como en un espejo deformante algunas circunstancias de la vida de la narradora o de personas cercanas a ella. En este

\footnotetext{
${ }^{1}$ Doy un ejemplo reciente de esto. En El cuervo blanco, Fernando Vallejo, el biógrafo, cuenta que se conserva un precario registro fonográfico de la voz de Rufino José Cuervo, el biografiado. El lector, instigado por ese dato, puede recurrir a YouTube, escuchar esa voz y así acceder a algo que el texto no le da, pero de algún modo señala apuntando a un afuera inconmensurable. Sin Internet, eso - escuchar la voz del biografiado- habría sido, para la mayoría de los lectores, imposible.

2 "Cada ocasión -las más de las veces un aniversario y las conmemoraciones que suscita- provoca un ramo de biografías más o menos concurrentes y que, salvo excepciones, ninguna se impone definitivamente a las otras, ni en el mercado historiográfico ni en el mercado editorial (...)” (Revel 2005: 2017, énfasis mío).
} 
sentido, esta novela puede ser leída como una suerte de respuesta postergada a las sospechas de Woolf sobre la posibilidad de mezclar hechos reales con otros que nadie puede verificar. En este caso, como también en la La luz negra, la mezcla no produce mutua destrucción sino un muy convincente ejemplo de hibridación genérica. En efecto, en El nervio óptico no solo la novela convive con la biografía, la autobiografía y el ensayo, sino que ella es también el resultado de sondear las posibilidades del diálogo de la literatura con otras artes, en este caso la pintura. Asimismo, esos pantallazos biográficos funcionan como atisbos de un puñado de vidas de artistas que el lector podrá seguir conociendo más allá de la novela. La luz negra, por su parte, es el relato de la búsqueda de información sobre una mujer a la que el lector solo conocerá por su apodo, "la Negra", una pintora talentosa y esquiva que además fue o habría sido una leyenda de la vida cultural de la ciudad de Buenos Aires de la década de 1960. Por la novela desfilan personas que realmente existieron y que habrían tenido con ella relaciones de diversa índole -Mariette Lydis, Oscar Masotta o Máximo Simpson- y a películas, libros y otras publicaciones en los que consta información, acaso no muy fidedigna, sobre esa mujer y sobre esas u otras personas que la conocieron. Estas dos novelas proponen una suerte de literatura expandida en el sentido de que el lector, a partir de esa casi siempre somera información biográfica que le ofrecen estos textos, podría embarcarse en una exploración que complete o amplíe -expanda- lo escrito por Gainza. Lo que propongo, en otras palabras, es que estas novelas parecen considerar y aun provocar, no importa aquí si programáticamente, la eventualidad de múltiples y virtuales adendas que el lector podría hacer a medida que avanza en la lectura ${ }^{3}$. ¿Cómo no ir a buscar en la web los cuadros que se nombran en $E l$ nervio óptico o más detalles sobre las vidas de los artistas que allí se mencionan? ¿Cómo no hacer algo similar a partir de los múltiples datos biográficos, a menudo crípticos, que ofrecen las páginas de La luz negra -un nombre, el título de un libro o la cita de uno cuyo título no se escribe- y conocer un poco más sobre la Negra o sobre el círculo artístico e intelectual del que participó hace ya varias décadas? $?^{4}$ No estoy, por supuesto, aseverando que ese sea el único modo de leer El nervio óptico o La luz negra, pero sí que es uno posible y además que, así, estas novelas comparecen narrativamente ante nuevas inflexiones de la lectura que habilitan en la contemporaneidad ciertos desarrollos de la tecnología digital.

El título de la segunda novela de Gainza, La luz negra, publicada en 2018, refiere, por un lado, a una especie de linterna que sirve a los especialistas para advertir con más

\footnotetext{
${ }^{3}$ Luis Chitarroni (2018) propuso en su reseña que a menudo en La luz negra el cuerpo del texto parece ocupado por informaciones que se asemejan a notas al pie.

${ }^{4}$ La relación entre biografía, Internet y el problema de los "hechos" aparece en el prólogo a un reciente libro, The Biographical Turn, en el que Hans Renders, Binne de Haan y Jonne Harmsma proponen: "Además, dado que las biografías ya no están motivadas principalmente por la reconstrucción y la recuperación de hechos (¿por qué haría tal cosa con Internet a mano?), la investigación biográfica ha entrado incluso en una fase claramente nueva" (2017: 4, traducción mía). Ya en su texto sobre la biografía, que es de la década de 1930, Woolf apunta a la proliferación de información producto de la cada vez mayor atención y registro de todo lo que hace una persona en su vida: "vivimos en una época en la que miles de cámaras apuntan -a través de los periódicos, las cartas y los diarios íntimos- a cada personaje desde todos los ángulos posibles” (2012: 158).
} 
precisión en una pintura ciertos detalles que permiten determinar si es o no falsa, y que usa Enriqueta Macedo, jefa de la narradora en la oficina de tasación del Banco Ciudad de Buenos Aires. Por otro, como lo adelanté, refiere a "la Negra", una artista plástica que habría sido no solo amiga de Enriqueta, sino también su cómplice en negocios vinculados a la puesta en circulación de falsificaciones de la obra de pintores más o menos famosos. Se trata de Renée Cuellar, un nombre propio que nunca aparece escrito en La luz negra 5 .

Desde las primeras páginas, la novela instala al lector ante problemas vinculados a las fronteras porosas entre lo original y lo falso, y la verdad y la mentira. A poco de iniciado el libro, se lee: "¿Una buena falsificación no puede dar tanto placer como el original? ¿En un punto no es lo falso más verdadero que lo auténtico?” (2018: 19). Desde allí en más, La luz negra formula ese tipo de paradojas y otras más o menos semejantes - "[la Negra] era una falsificadora original" (37) o "A veces me pregunto si la falsificación no es la única gran obra del siglo" (81) -, y establece sintonía con las reflexiones que, para dar un ejemplo célebre, postula el documental de Orson Welles F for Fake, de 1973, al que se menciona en este libro como "la película que [es] al mundo de la falsificación lo que El padrino al mundo de la mafia" (21).

Luego de la muerte de Enriqueta Macedo, su jefa y amiga, la narradora de este libro -solo se conocerá de ella el "nombre de fantasía" con el que se registra, en el comienzo de la novela, en el hotel Étoile del barrio porteño de Recoleta: María Lydis- se embarca en el proyecto de escribir una biografía de la Negra. Para comenzar cuenta con algunos datos, que recuerda no demasiado fielmente (19), que le fueron trasmitidos por Enriqueta durante sus años de amistad. En principio, el objetivo es más o menos claro: "Buscaría a la Negra, revolvería cielo y tierra si eso era necesario. Hurgaría hasta en el último rincón, y si seguía viva, la encontraría, la despojaría de sus secretos y todo eso lo convertiría en un libro. Siempre fui muy fisgona en todo lo referente a la naturaleza del genio" (82).

En este sentido, podría computarse esta novela como un ejemplo más de aquellos textos biográficos a los que el crítico brasileño Antonio Marcos Pereira (2018) denominó, en contraste con las formas canónicas y monumentales de la biografía, "biografías del proceso" y que estarían representadas por textos que no disimulan el trabajo y, en especial, las incertidumbres que acarrea la escritura de una biografía, sino que los exhiben y hacen de ellos, antes que de la vida que cuentan, su principal atractivo. La luz negra es menos una biografía de la Negra que la narración de una búsqueda que podría haber dado como resultado esa biografía, pero que no lo da. Esa biografía reveladora -ese libro que se anuncia en el quinto capítulo- no se escribe y no se escribirá. Por ello, La luz negra es lo contrario de En busca del tiempo perdido, porque mientras esta última es el minucioso relato de cómo se llega a escribir un libro la primera es sobre cómo se llega a decidir no escribirlo; aunque, como se verá más adelante, al igual que en la de Proust, en la novela de Gainza es también muy importante el tiempo perdido, pero en un sentido diferente.

\footnotetext{
${ }^{5}$ Algunas precisiones sobre la vida de Renée Cuellar y sobre la construcción de su leyenda biográfica pueden leerse en el retrato "La suprema negra”, escrito por Inés Moguillanes (2020).
} 
La luz negra narra -o, con más precisión, aparenta narrar- el abandono del proyecto de escritura de un libro biográfico por falta de voluntad en quien emprende esa tarea. En efecto, sobre el final, cuando se refiere a la novela inhallable que habría dado origen a la película Tiro de gracia, de Ricardo Becher, en la que hay un personaje al que llaman la Negra que estaría inspirado en "mi Negra", para darle un nombre a su pereza la narradora convoca la figura del "biógrafo indolente" (125) y además confiesa:

Un académico bien formado hubiera revuelto cielo y tierra hasta dar con el libro, pero a esa altura yo me consideraba "el biógrafo indolente": si se complicaba por demás, lo dejaba ir. No tenía la paciencia que se estima invaluable, el hábito de cotejar materiales, de sopesar testimonios contradictorios, al fin de cuentas buscaba lo más vital, lo que iba a precisar, no más. Tenía una coartada para mi pereza de oso, la sigo teniendo: los agujeros en una vida no son los espacios negativos que el biógrafo deba rellenar compulsivamente. Ellos también pueden ser cenotes, pozos subterráneos de aguas inciertas, la terra infirma donde prolifera la leyenda. En cuanto a la Negra, escaseaban los datos y sobraban las fabulaciones. (125-126)

Pero la pereza, aquí, no es más que una excusa y las razones para, finalmente, no escribir una biografía son de índole menos personal de lo que parece en un principio. La renuncia a escribir una biografía no radica tan solo en La luz negra en una incapacidad personal, en una falta de voluntad -la biografía, entonces, como género de la perseverancia y de la paciencia y, por lo tanto, en varios sentidos oneroso-, sino también, y fundamentalmente, en un convencimiento -en un saber- que se le revela poco a poco a la narradora durante la pesquisa previa a la escritura de esa vida. Ese saber puede resumirse así: la mejor relación que se puede tener con una vida no es conocerla acabada y exhaustivamente, sino apenas intuirla, sospecharla, atisbarla a la distancia, fuera de foco. Solo de este modo una vida podrá seguir interesando: si continúa siendo un misterio, una revelación que se aplaza. Esta novela de Gainza viene así a poner en crisis la cuestión de "los hechos" a propósito de la biografía, para decirlo con las palabras de Woolf, o del "qué pasó exactamente", para decirlo con las de Shelston. Por eso, un poema de Hâjî Abdû ElYezdî sirve en La luz negra, precisamente, para asegurar que los hechos son "la más inútil de las supersticiones" (126).

La luz negra no es, por lo tanto, como de manera provisoria sugerí más arriba, meramente una novela sobre el abandono del proyecto de escritura de una biografía por indolencia o pereza; vale decir, no es tan solo una novela más sobre el I would prefer not to. Antes bien, es una interpelación novelística de la biografía que consiste en la práctica de una poética biográfica que corteja la incertidumbre, el esbozo y lo preliminar: lo inexacto. Pretender sacar a la luz alguna verdad sobre el biografiado, dar precisiones absolutas sobre los hechos de su vida, despojarla de secretos, puede concluir en la decepción, en la pérdida de atractivo.

No obstante ese convencimiento, en este libro se narran varias vidas. Por ejemplo, la vida de Mariette Lydis, la pintora de origen austriaco de la que la Negra habría falsificado varios cuadros y de la que acaso fue también su modelo y su amante. Pero esa vida, en el 
capítulo "La galería de mujeres iluminadas", no se narra de manera convencional, sino a través de los indicios sobre Lydis que ofrece el catálogo de la subasta de una serie de objetos que le pertenecieron y que permiten sospecharla, vislumbrarla. Se trata del boceto de una vida, de lo biográfico en la bruma, de fantasmagorías biográficas. Lo mismo ocurre con otras vidas a las que se alude en La luz negra: por ejemplo, la de traductora Matilde Horne, de la que se escribe su nombre pero no su apellido, o la de Federico Manuel Vogelius, que el lector entrevé, en el capítulo titulado "Un tal Ramos", a partir de algunos extractos del expediente de "mil fojas amarillentas" del juicio que le entabló un ex socio, Damián Bendahan, por venta de cuadros falsos en la década de 1960 y algunos pocos datos más que la narradora atiborra en el primer párrafo del capítulo siguiente, "La virtud del cocodrilo".

Ese capítulo construido prioritariamente con extractos de un expediente judicial incluye, y me interesa hacer énfasis en esto, la reproducción del identikit, armado según "los datos aportados por el señor Vogelius" (111), del rostro de un hombre de apellido Ramos, del que no se da su nombre de pila, y que fue, según aquel, el responsable de la circulación de las pinturas falsas que compró su socio, Bendahan, y también él. A propósito de ese identikit se plantean dos posibilidades: que se trate del de alguien que en realidad no existió, y que Vogelius inventó para restarse culpabilidad, o que se trate del de alguien que efectivamente existió, pero que por ser una imagen armada en base a recuerdos de hechos sucedidos tiempo atrás -el Diccionario de la RAE propone el sintagma "retrato hablado" como equivalente castellano de esta palabra- apenas se asemeje al verdadero rostro de Ramos ${ }^{6}$. Ese doble problema a propósito del identikit de Ramos es el que, en otra escala, postula toda la novela a propósito de la Negra: ¿es esta mujer legendaria una completa fabulación, un ser inventado que, a la manera de un cuadro falso que quiere pasar por original, y lo logra, se escurre en la realidad (se filtra entre los nombres reales de Oscar Masotta, Juan Rodolfo Wilcock o Federico Vogelius) o se trata más bien, y considero que esta es la posibilidad que más le interesa a Gainza, de que a lo sumo se puede postular un identikit biográfico de la Negra, uno que genera menos seguridad que incertidumbre porque también, como el del evasivo señor Ramos, está armado en base a recuerdos que no son confiables, como no lo son nunca los recuerdos? En este sentido, ya en las páginas finales del libro, la narradora plantea que "una biografía por naturaleza es inenarrable" (127) porque la gente o no recuerda mucho o recuerda mal: "ni siquiera se acuerda de qué ha tomado al desayuno" (126). Como Jorge Luis Borges en Evaristo Carriego, Gainza en La luz negra proclama la dificultad de toda empresa biográfica a propósito del problema de la falibilidad de la memoria y del recuerdo (ese archivo oral es el que más le interesa a Gainza). Así, La luz negra trabaja con el mismo problema que Borges planteó hace ya casi un siglo: "Que un individuo quiera despertar en otro individuo recuerdos que no pertenecieron más que a un tercero es una paradoja evidente. Ejecutar con despreocupación esa paradoja es

\footnotetext{
${ }^{6}$ En sus declaraciones, Vogelius asegura que Ramos tenía bigotes (110); en contraste, Saúl Posternak, un contador empleado de Vogelius, afirma que "no recuerda si tenía bigotes pero cree que no" (111). El rostro que se ve en el identikit no tiene bigotes.
} 
la inocente voluntad de toda biografía" (1930: 31). Y también como Borges en esa muy heterodoxa biografía, pese a que debilita críticamente la idea misma del género, como apuntó Beatriz Sarlo (1995) a propósito de aquel, la vida de todos modos se escribe, pero antes como "boceto" -tomo este término de un reportaje que le hicieron a Gainza que citaré más adelante de manera más extensa- que como texto preciso y, menos aún, definitivo ${ }^{7}$. En La luz negra se cuentan vidas a pesar del convencimiento de que se trata casi de un ejercicio fútil y aun absurdo: "No hay vida destinada a ser preservada y, a menos que uno sea un faraón, no tiene que aspirar a convertirse en momia" (99), según la afirmación de Joseph Brodsky que cita la narradora.

En su reseña de esta novela, el crítico Kit Maude señaló que:

Ya sea para subvertir las expectativas del lector o quizás debido a una falta de convicción en el curso elegido, la segunda mitad del libro se va disolviendo en una serie de vińetas sin forma. Nuestra narradora decide investigar la vida de la Negra para una biografía eventual pero, como ella misma reconoce, no podría ser más floja en su cometido. Aunque todavía hay momentos buenos, algunas chispas del período tan fascinante de los sesenta porteńos y sus supervivientes, la verdad es que no hay mucha gracia en un Poirot indiferente, un Marlowe perezoso o un objetivo en última instancia decepcionante. (2019)

Considero por mi parte que esa cualidad informe -Maude habla de "viñetas sin forma" - de la segunda mitad de La luz negra es deliberada y se corresponde precisamente a esa apuesta por lo brumoso o lo fuera de foco; es decir, cierto desdibujamiento del texto en los tramos finales -cierta cualidad deshilachada de esta ficción- sería otra inflexión, en este caso del orden de lo estructural, de esa apuesta narrativa por lo indefinido. Además, no se trata de que el "objetivo" sea "decepcionante" en este caso particular, sino, de manera más general, de que la narradora intuye que el objetivo al que, en un principio, quería llegar -revelar la verdad sobre la Negra, sus secretos- será decepcionante al igual que cualquier objetivo de llegada que se pueda proponer cualquier biógrafo, y no solo ella para este específico caso. Por lo demás, he intentado argüir que el abandono de la escritura de la biografía se debe, antes que a la pereza o a la indiferencia, al progresivo acceso a un saber deceptivo sobre el género biográfico. En este sentido, habría que agregar que el estatuto de leyenda que se le adjudica a la Negra en esta novela se amplía a esas otras vidas a las que

\footnotetext{
${ }^{7}$ Como la narradora de La luz negra en ese fragmento sobre el "biógrafo indolente" que transcribí más arriba, la propia Gainza, al referirse a la reconstrucción de la Buenos Aires de la década de 1960 en La luz negra, se refirió a su preferencia por el boceto: "No pretendía ser un homenaje. (...) No quería reconstruir, solo dar algunas pinceladas sueltas y abiertas, lo mío es el boceto. Para la reconstrucción minuciosa y hollywoodense tenés que ser muy virtuoso. (...) Yo soy muy limitada como escritora como para intentar eso. Si me tiro al agua necesito ver la orilla" (Tentoni 2018). Como la narradora de su novela, acá la apuesta fuerte por una poética del "boceto" está presentada como una limitación antes que como un convencimiento. Se trata, por supuesto, antes que del sincero señalamiento de una limitación de una modulación elegante de la captatio benevolentiae.
} 
en sus páginas se alude precisamente porque ese modo brumoso de contarlas - de apenas contarlas- las hace legendarias.

En La luz negra esta práctica idiosincrásica de la escritura de vidas recibe el nombre de gentileza biográfica. "No esperen nombres, estadísticas, fechas", asegura la narradora al comienzo del libro, para enseguida agregar: "A esta altura de mi vida yo aprecio las gentilezas, prefiero que me digan: 'Supongamos que así sucedió”' (10). El experimento biográfico que se realiza en La luz negra debe leerse, entre otras cosas, como la puesta en narración de una apología de la biografía como acercamiento, como esbozo o boceto, y no como texto revelador que codicia fastidiosamente la exhaustividad, la claridad y la nitidez: la revelación fulgurante. La biografía, entonces, como terra infirma y no como terra firma. Una gentileza biográfica que, en su ejercicio, rehúye el prepotente y al mismo tiempo sospechoso "Esto fue asi”" (10). La luz negra pertenece a ese tipo de literatura biográfica que traman libros como En busca del barón Corvo, de A. J. A. Symons, El loro de Flaubert, de Julian Barnes, Rimbaud en Java, de Jamie James o, para nombrar textos argentinos y más recientes, Sobre Sánchez, de Osvaldo Baigorria, y Mastronardi, de Miguel Ángel Petreca ${ }^{8}$. Se trata, en todos los casos, de textos biográficos que hacen hincapié en el desconcierto, en la búsqueda, en la conjetura y en la sospecha y que se alejan de la terra firma, y también de la "coerción siniestra" (10), que ofrecen las biografías más adocenadas y prepotentes que de todos modos, por supuesto, seguimos leyendo y reseńando y tampoco consideramos que deban dejar de escribirse.

En contraste con el área de la pintura, en donde es posible discernir con cierta exactitud la autenticidad de una obra, no hay "luz negra" o alguna habilidad de iniciado que puedan dar certidumbre acerca de la autenticidad de un texto biográfico ${ }^{9}$. Por lo tanto, el biógrafo deberá, si es gentil, hacernos saber que lo que narra es siempre, inevitablemente, una suposición: una aproximación, una búsqueda que nunca concluye porque no puede y no debe concluir. La relación paradójica entre el arte auténtico y el falsificado es, entonces, el macguffin temático de esta novela. Aunque aparenta serlo, La luz negra no es un libro sobre las potencias de lo falso, como sí lo son, por ejemplo, además de F for Fake, la biopic sobre la biógrafa y falsificadora de documentos biográficos Lee Israel Can You Ever Forgive Me?, dirigida por Marielle Heller, o Rolling Thunder Revue. A Bob Dylan Story, el documental de Martin Scorsese en el que es central la cuestión de la máscara y de la falsificación de unas vidas $^{10}$. La luz negra es, en todo caso, un libro sobre las potencias de lo inexacto.

\footnotetext{
${ }^{8}$ En su análisis de Sobre Sánchez, Julia Musitano (2018) trabaja con la cuestión, a propósito de Baigorria como biógrafo, de la renuncia, de la pereza y del abandono. La noción de experimento biográfico que utilizo para referirme a la novela de Gainza lo tomo del subtítulo de la novela de A. J. A. Symons, cuyo título original en inglés es: The Quest for Corvo: An Experiment in Biography.

${ }^{9}$ A no ser que venga en auxilio de esa escritura lo sobrenatural, como el caso que se narra en La luz negra acerca de las "condiciones misteriosas" que habrían determinado la escritura de una biografía de William Blake por parte de Alexander Gilchrist y, luego, de su esposa, Anne (99-101).

10 "Las potencias de lo falso" es el título de un capítulo de La imagen tiempo en el que Gilles Deleuze (2005) analiza, entre otras, la obra de Orson Welles.
} 
La novela -que bien podría haberse titulado En busca de la Negra- viene a manifestar in extremis que la labor biográfica procura un placer más intenso durante el proceso de búsqueda, de hurgueteo, de fisgoneo, que en el descubrimiento final al que pueden conducir esas actividades. ¿̇Acaso el que más se divierte, siempre, no es el biógrafo? En La luz negra, escribir el proceso es también considerar la cualidad en principio indeterminada de aquello que se busca $-\mathrm{y}$ por ello la narradora se refiere a este con el término alemán Sehnsucht (103), que designa la búsqueda de algo indefinido- y, asimismo, la muy probable decepción que la conclusión de ese proceso pueda deparar. A propósito de esto, la narradora cuenta que cuando finalmente pudo ver una foto "ligeramente fuera de foco" (otra vez lo nebuloso, lo difuso, la bruma) donde aparece, aunque no en primer plano, la Negra, sintió que sonaba una "alarma": "Me hizo sentir como el amante que quiere saber todo sobre su amada aun cuando sabe que esa curiosidad lleva en sí el germen de la decepción" (103). Por ello -vale decir, no solo por indolencia, sino por sabiduría-, elige detenerse antes de que ocurra irreparablemente esa intuida decepción: “QQué hermosa pérdida de tiempo había resultado mi búsqueda hasta ahora! Una patética biografía cuya falta de resolución me resultaba extrañamente gratificante" (133). En última instancia, entonces, en La luz negra se argumenta que la buena biografía, la gratificante, es la que no se concluye, la que se abandona. La "falta de resolución" a la que refiere la narradora con júbilo debe entenderse como que la búsqueda felizmente no concluyó en nada preciso (por ejemplo, una biografía de la Negra), pero también en el sentido en el que se habla de la resolución de una fotografía a propósito de su mayor o menor nitidez. El género, por tanto, es prioritariamente un hurguetear que debe, si es posible, cesar antes de la decepción: "Fue así como un día me prometí a mí misma que dejaría de buscar" (134). ¿Es preferible el boceto al retrato terminado, el borrador al texto final, lo turbio a la nitidez, el secreto aludido al revelado? La biografía antes como plan de fuga que como anhelo de llegada, de conclusión, de "resolución". Considerar la posibilidad de escribir una biografía implica, en consecuencia, estar dispuesto a perder hermosamente el tiempo y quizá no mucho más que eso. No se trata, entonces, de ir en busca del tiempo perdido sino de cómo se perdió el tiempo al ir en busca de algo ${ }^{11}$.

En esta novela la aspirante a biógrafa recorre el camino que va del inocente y despreocupado deseo de sacar a la luz los "secretos" (82) de una vida a descubrir que es preferible que permanezcan ocultos, no revelados o a lo sumo insinuados. La narradora aprende eso al menos de dos maneras: gracias a su experiencia de búsqueda que se detiene antes de la "decepción" y, también, a la lección que se cifra en el relato que le cuenta un

\footnotetext{
${ }^{11}$ La propia novela procura que el lector pierda el tiempo junto con la narradora. El capítulo "Un tal Ramos", en el que se acumulan fragmentos del expediente del juicio a Vogelius, no aporta ningún dato sobre la Negra. El lector, así, al igual que la narradora, pierde el tiempo leyendo un texto que nada aporta a la investigación. En el mismo sentido, cuando narra la historia de la biografía de William Blake, la narradora consigna que la contará aunque "se relaciona apenas con mi tema principal" (99). En este caso, la pérdida del tiempo de la narradora es también una recuperación del tiempo con su amiga muerta, Enriqueta: un modo indirecto de seguir hablando con ella.
} 
huésped del hotel Étoile acerca de un cocodrilo de piel superluminosa que, al abandonar el lecho barroso y oscuro del río y decidir exhibirse a plena luz del sol, arruinó el atractivo de su piel y además terminó decepcionando a quienes en principio lo adularon (132-133). Es por esta razón que la narradora, antes que perseguir una respuesta, prefiere, por ejemplo, quedarse con la interrogación: ¿la Negra convivió o no con un cocodrilo que acaso se llamaba Abdul? Así, sobre el final, resuelve que, para ella, la Negra, perpetuamente, seguirá siendo "una nube en el horizonte" (103): un retrato brumoso de Francis Bacon y no uno hiperrealista de Jan Van Eyck. Algo semejante se sugería ya en un capítulo de El nervio óptico, en el que se asegura: "¿quién no arrastra algún misterio en su biografía? Hay detalles que se pierden en la noche de los tiempos y es mejor así: terminar de entender las cosas vuelve rígida la mente" (2017: 51, énfasis mío). Sacar a la luz, acercarse demasiado, abrir puertas que no se deben abrir o poner en foco lo desenfocado-terminar de entender las cosas- son faenas que pueden resolverse en el desencanto ${ }^{12}$. Luz, entonces, pero luz negra. De lo que se trata, en última instancia, es de la ponderación de lo arcano, de lo que debe permanecer escondido o apenas revelado. La luz negra incluso hace eso insistentemente con un elemento que, según lo propuso Pierre Bourdieu, es decisivo en el andamiaje de cualquier "ilusión biográfica": el nombre propio ${ }^{13}$. Al menos dos son los nombres propios que no se dicen, que se escamotean, o que solo se dicen parcialmente en este libro: el de la narradora y el de la Negra; vale decir, nada menos que los de la biógrafa y biografiada. Y esos no son los únicos casos de opacamiento onomástico que partica esta novela: de quien fue pareja de la Negra, Oscar Masotta, se dice el nombre de pila pero no el apellido. Por su parte, hay además un apellido que se escribe levemente mal, con una letra de menos, como si fuera menos un apellido que su identikit: la narradora escribe dos veces, en la misma página, "Correa" (81) y no "Correas" o "Carlos Correas", el autor del ensayo biográfico La operación Masotta, al que se cita textualmente sin mencionar su título. Al respecto, me resulta al menos por dos razones especialmente relevante que en un artículo titulado "Falsificadores y truhanes", el escritor y periodista cultural Hugo Beccacece, quien aclara que conoció "a varias de las personas que inspiraron los personajes de la narración y que conservan en la novela sus nombres verdaderos", con la voluntad de colmar ese opacamiento onomástico que inquieta

\footnotetext{
${ }^{12}$ Las puertas son importantes en la novela: por ejemplo, la puerta de la casa de Enriqueta que la narradora abre "con el truco de la moneda, secreto que no puedo revelar acâ" (23, énfasis mío) o la puerta prohibida que abre Martín en la casa de la Negra (127).

${ }^{13}$ En "La ilusión biográfica", Pierre Bourdieu hace énfasis en la importancia que tiene el nombre propio en la construcción de lo que denomina, sin disimulado desdén, "historia de vida". Para Bourdieu el nombre propio es un aglutinante de los distintos hechos y posiciones que conforman una vida: “(...) garantiza la identidad del individuo biológico en todos los campos posibles en los que interviene en tanto agente, es decir, en todas sus historias de vida posibles" (1997: 80). Por lo demás, en la emergencia de la novela, como lo analiza Ian Watt, es central la importancia de los nombres propios que no parecen referir a un "tipo" y sí a una persona, a un individuo. La identidad onomástica es central, para ese teórico, en la constitución de la novela. Al respecto, Watt cita un texto de Henry James sobre Anthony Trollope en el que aquel postula que no respetar esa tradición -la de darles a los personajes nombres propios- puede destruir la creencia del lector en ese personaje. Para Watt los nombres propios son un elemento importante en la constitución del realismo novelesco (2000: 19-21).
} 
La luz negra, sostiene que el "nombre real [de la Negra] era probablemente María Vargas" (2018). No obstante, en la novela se afirma que María Vargas no era el nombre de la Negra, sino el de la actriz que en la película Tiro de gracia encarna a un personaje quizá inspirado en ella $(125)^{14}$. Además, en la opción por el adverbio "probablemente", al tiempo que busca reponer algo que la novela omite, Beccacece también juega el juego gentil del supongamos que postula aquella. Y también, el de decir más de lo que se dice en el texto -expandirlo, amplificarlo- o de verificar -uso el mismo verbo que Virginia Woolf- lo que en él sí se dice.

$\mathrm{Si}$, entonces, para finalizar, volvemos a aquello de que a la novela le correspondería, según Henry James y D. H. Lawrence, una forma más elevada de la verdad que a la biografía, habría que concluir en que La luz negra se permite la postulación de ciertas verdades sobre la biografía -entre otras, su condena inevitable a la incertidumbre y su carácter frecuentemente deceptivo- que ella misma no se atrevería a confesar o, peor, sería incapaz de advertir. Esta novela de María Gainza pondría así en evidencia el estatuto despreocupado e inocente de la biografía que porfiaría una y otra vez en hacer lo que no se debe o lo que no se puede. Un género que, como el "paranoico" o el "romántico", no sabe que "la vida es la antiforma" (98). En este caso no se trata, pues, de considerar la biografía como "novela que no se atreve a decir su nombre”, según propuso Roland Barthes (Dosse 2007: 307), sino como el género que dice lo que la biografía no se atreve a decir. Y también, complementariamente, como el que puede atreverse a no decir lo que una biografía debe sí o sí decir: los nombres propios del biógrafo y del biografiado. De este modo, La luz negra se presenta como una transgresión, por lo demás gentil y nada crispada, de unos cuantos principia biographica.

\section{Obras Citadas}

Beccacece, Hugo. 2018. "Falsificadores y truhanes". La Nación, 17/12/2018. En: https:// www.lanacion.com.ar/opinion/falsificadores-y-truhanes-nid2203129.

Borges, Jorge Luis. 1930. Evaristo Carriego. Buenos Aires: Gleyzer.

Bourdieu, Pierre. 1997. "La ilusión biográfica". En Razones prácticas: Sobre la teoría de la acción. Barcelona: Anagrama. 74-83.

Chitarroni, Luis. 2018. "La luz negra, de María Gainza. Cuadros de una exhibición maestra”. Revista N, 16/11/2018. En: https://www.clarin.com/revista-enie/literatura/ cuadros-exhibicion-maestra_0_BdN6g4qpT.html.

Deleuze, Gilles. 2005. La imagen tiempo. Estudios sobre cine 2. Buenos Aires: Paidós.

Derrida, Jacques. 1994. Márgenes de la filosofía. Madrid: Cátedra.

Dosse, François. 2007. La apuesta biográfica. Escribir una vida. Valencia: PUV.

Gainza, María. 2018. La luz negra. Buenos Aires: Anagrama. . 2017. El nervio óptico. Buenos Aires: Anagrama.

${ }^{14}$ IMDB informa que María Vargas fue actriz de la película de Becher y, también, al menos de otra película: ¡Ufa con el sexo!, de Rodolfo Kuhn. 
Maude, Kit. 2019. "La luz negra”. Revista Otra Parte, 21/3/2019. https://www.revistaotraparte.com/literatura-argentina/la-luz-negra/.

Moguillanes, Inés. 2020. "La suprema negra". La Agenda Revista, 2/10/2020. En: https:// laagenda.buenosaires.gob.ar/post/630691759454896129/la-suprema-negra.

Musitano, Julia. 2018. "Sobre Sánchez. Biografía y abandono". En Nora Avaro, Judith Podlubne y Julia Musitano, Eds., Un arte vulnerable. La biografía como forma. Rosario: Nube Negra. 165-175.

Pereira, Antonio. 2018. "La poética del proceso". En Nora Avaro, Judith Podlubne y Julia Musitano, Eds., Un arte vulnerable. La biografia como forma. Rosario: Nube Negra. 19-30.

Renders, Hans, De Haan, Binne y Harmsma, Jonne. 2017. The Biographical Turn. Lives in History. London-New York: Routledge.

Revel, Jacques. 2005. "La biografía como problema historiográfico". En Un momento historiográfico: trece ensayos de historia social. Buenos Aires: Manantial. 217-228

Sarlo, Beatriz. 1995. Borges, un escritor en las orillas. Buenos Aires: Ariel.

Shelston, Alan. 1977. Biography. Londres: Methuen.

Tentoni, Valeria. 2018. "Lo mío es el boceto. Reportaje a María Gainza". Blog "Eterna cadencia". Web: https://www.eternacadencia.com.ar/blog/contenidos-originales/entrevistas/item/maria-gainza-lo-mio-es-el-boceto.html.

Watt, Ian. 2000. The Rise of the Novel. Berkeley \& Los Angeles: University of California Press.

Woolf, Virginia. 2012. "El arte de la biografía". En La muerte de la polilla y otros ensayos. Buenos Aires: La Bestia Equilátera. 152-160. 
